\title{
Bulk Nanostructuring Intermetallic Composite Material
}

\author{
V. E. Ovcharenko ${ }^{1,2, a)}$, S. G. Psakhie ${ }^{1,2, b)}$, Yu. F. Ivanov ${ }^{2,3, c)}$, \\ K. V. Ivanov, ${ }^{1,}$, and E. N. Boyangin ${ }^{1, e)}$ \\ ${ }^{1}$ Institute of Strength Physics and Materials Science SB RAS, Tomsk, 634055, Russia \\ ${ }^{2}$ National Research Tomsk Polytechnic University, Tomsk, 634050, Russia \\ ${ }^{3}$ Institute of Heavy-Current Electronics SB RAS, Tomsk, 634055, Russia \\ a) Corresponding author: ovcharenko.ove45@mail.ru \\ ${ }^{b)}$ psakhie.sp@ispma.tsc.ru \\ c) ivanov.yufi55@mail.ru \\ d) ivanov.ikv@ispms.tsc.ru \\ e) boyangin.jeck2000@list.ru
}

\begin{abstract}
The article states the results of a study of the impact rendered by the plastic strain occurring in a hightemperature synthesis product during the thermal explosion of a nickel-aluminum powder mixture on the grain structure, strength and ductility of the $\mathrm{Ni}_{3} \mathrm{Al}$ synthesized intermetallic compound.
\end{abstract}

Keywords: intermetallic compound $\mathrm{Ni}_{3} \mathrm{Al}$, high-temperature synthesis, plastic deformation, ultimate strength and deformation-to-fracture

\section{INTRODUCTION}

As structural alloys for high-temperature applications, $\mathrm{Ni}_{3} \mathrm{Al}$ intermetallic compound-based refractory nickel alloys hold leading positions in terms of their production volume and use in chemical industry, power industry, aircraft building, space technology, etc. The $\mathrm{Ni}_{3} \mathrm{Al}$ intermetallic compound ( $\gamma^{\prime}$ phase, ordered solid solution) is the main strengthening phase, and its behavior under load largely determines the heat-resistant alloy's lifetime in general. Therefore, the $\mathrm{Ni}_{3} \mathrm{Al}$ intermetallic compound is a subject of systematic studies [1]. The use of complex doping is a classical approach to increasing the strength and ductility of the intermetallic compound, including hightemperature conditions, but the doping's potential has been virtually exhausted by now. The use of strength and ductility improving methods in metals and alloys by atomizing the grain structure under severe plastic strain seems to be impossible either, as the $\mathrm{Ni}_{3} \mathrm{Al}$ intermetallic compound is characterized by a high susceptibility to brittle intercrystalline fracture. A unique opportunity to obtain the plastic strain of the $\mathrm{Ni}_{3} \mathrm{Al}$ intermetallic compound is to expose it to loading it from the melt state in the narrow time interval of intermetallic compound crystallization under the conditions of high-temperature synthesis (SHS) through the thermal explosion of the nickel-aluminum powder mixture of stoichiometric composition (Fig. 1(a)) [2].

The purpose of this study is to investigate the grain formation morphology in terms of its dependence on the degree of the plastic strain of the high-temperature synthesis product as well as its effect on the strength and ductility of the $\mathrm{Ni}_{3} \mathrm{Al}$ intermetallic compound.

\section{EXPERIMENTAL PROCEDURES}

The effect of severe plastic deformation of a high-temperature synthesis product on the grain structure of the $\mathrm{Ni}_{3} \mathrm{Al}$ intermetallic compound synthesized under pressure was observed on intermetallic compound ingots synthesized under pressure in the thermal explosion mode in a nickel $(\sim 2.0 \mu \mathrm{m})-$ aluminum $(\sim 1.0 \mu \mathrm{m})$ powder mixture of a stoichiometric composition in a conical open-type mold (Fig. 1(b)).

International Conference on Physical Mesomechanics of Multilevel Systems 2014

AIP Conf. Proc. 1623, 459-462 (2014); doi: 10.1063/1.489898

(C) 2014 AIP Publishing LLC 978-0-7354-1260-6/\$30.00 


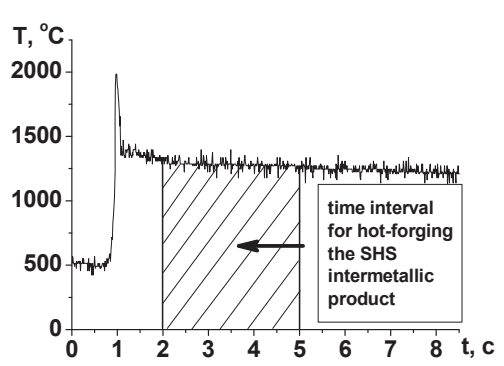

(a)

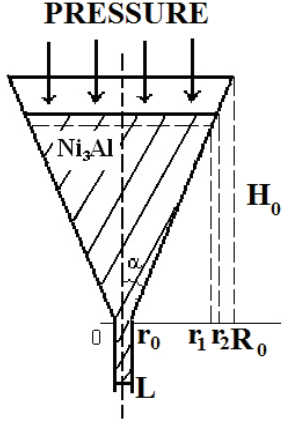

(b)

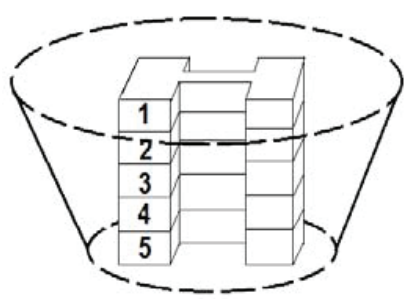

(c)

FIGURE 1. Thermogram of the $3 \mathrm{Ni}+\mathrm{Al}$ powder mixture's thermal explosion demonstrating the SHS intermetallic product strain time interval (a); the SHS process flow chart for an intermetallic ingot with severe plastic deformation of the SHS product in a conical open-type mold (b); the and method of obtaining samples for the intermetallic compound $\mathrm{Ni}_{3} \mathrm{Al}$ tensile tests with various degrees of the SHS product's plastic strain (c)

The mold diameter was $58.0 \mathrm{~mm}$ at the upper part and $7.0 \mathrm{~mm}$ at the bottom, the mold was $50 \mathrm{~mm}$ high, and the bottom aperture diameter was $7.0 \mathrm{~mm}$. A sample of the rectangular cross section was cut out of the conical intermetallic compact and cut into $30 \times 10 \times 1.5 \mathrm{~mm}$ tensile test pieces with a $10 \cdot 4 \mathrm{~mm}$ gage length (Fig. 1(c)).

The plastic strain of the $\mathrm{Ni}_{3} \mathrm{Al}$ intermetallic compound during its high-pressure synthesis under pressure in a conical mold with subsequent high-temperature synthesis product extrusion was calculated for five equally thick transverse layers of synthesized conical intermetallic compact (Table 1).

The resultant phases in different samples of the intermetallic compound were characterized by the X-ray diffraction (XRD) with a $\mathrm{Cu} \mathrm{K \alpha}$ radiation at $40 \mathrm{kV}$ and $40 \mathrm{~mA}$. The microstructure of intermetallic alloys was examined using optical metallography (Neophot 32), scanning electron microscopy (SEM-515 scanning electron microscope by Philips with EDAX ECON IV energy-dispersive analyzer of element composition), and transmission diffraction electron microscopy (JEM-2100). The intermetallic compound test specimens were prepared for transmission diffraction electron microscopy by surface ion etching. The samples were tested for tensile strength on the INSTRON machine at a $0.2 \mathrm{~mm} / \mathrm{min}$ elongation rate.

\section{RESULTS AND DISCUSSION}

\section{Microstructure Characteristic}

The main phase of all the examined samples of the synthesized alloy is the $\mathrm{Ni}_{3} \mathrm{Al}$ intermetallic compound, which is confirmed by the presence of superstructure reflections suggesting an ordered state of the material in appropriate micro diffraction patterns (Fig. 2).

The examination of the grain structure of the $\mathrm{Ni}_{3} \mathrm{Al}$ intermetallic compound samples synthesized under pressure under plastic strain in a conical mold showed that the plastic strain of the synthesis product results in the formation of a bimodal grain structure represented by micron size $(10 \mathrm{~mm}$ or more) grains and "multigrains" consisting of submicron $(0.1-0.5 \mu \mathrm{m})$ grains in the intermetallic compound (Fig. 3).

An examination of the fine structure of the synthesized intermetallic compound by transmission diffraction electron microscopy showed that the upper layer of the conical intermetallic ingot is a multiphase material. At the initial degrees of high-temperature synthesis product strain, the bimodal grain structure of the synthesized intermetallic compound consists of $\gamma^{\prime}$ phase grains and the areas of submicron structure containing 10-.50 nm particles of subsequent phases $\left(\mathrm{Al}_{2} \mathrm{O}_{3}\right.$ and an insignificant amount of $\mathrm{Ni}_{2} \mathrm{Al}_{3}$ and $\left.\mathrm{NiAl}\right)$ located at $\gamma^{\prime}$ phase grain joints and at $\gamma^{\prime}$ phase grain boundaries.

TABLE 1

\begin{tabular}{lllll}
\hline $\begin{array}{l}\text { Layer number in the intermetallic compact starting from the upper part } \\
\text { of the cone }\end{array}$ & 1 & 2 & 3 & 5 \\
\hline $\begin{array}{l}\text { Degree of plastic strain of the intermetallic synthesis product in the } \\
\text { layer, } \%\end{array}$ & 4.2 & 5.6 & 7.4 & 10.6 \\
\hline
\end{tabular}




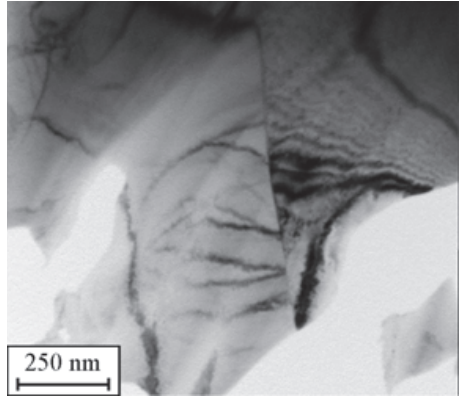

(a)

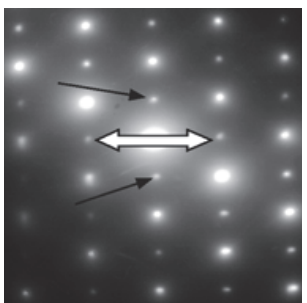

(b)

FIGURE 2. Electron microscope image of the structure of the $\mathrm{Ni}_{3} \mathrm{Al}$ intermetallic compound (a); electron diffraction pattern obtained from the left grain (b). Arrows indicate superstructure reflections in the electron diffraction pattern: dark arrows $-\{001\} ;$ light arrows $-\{110\}$
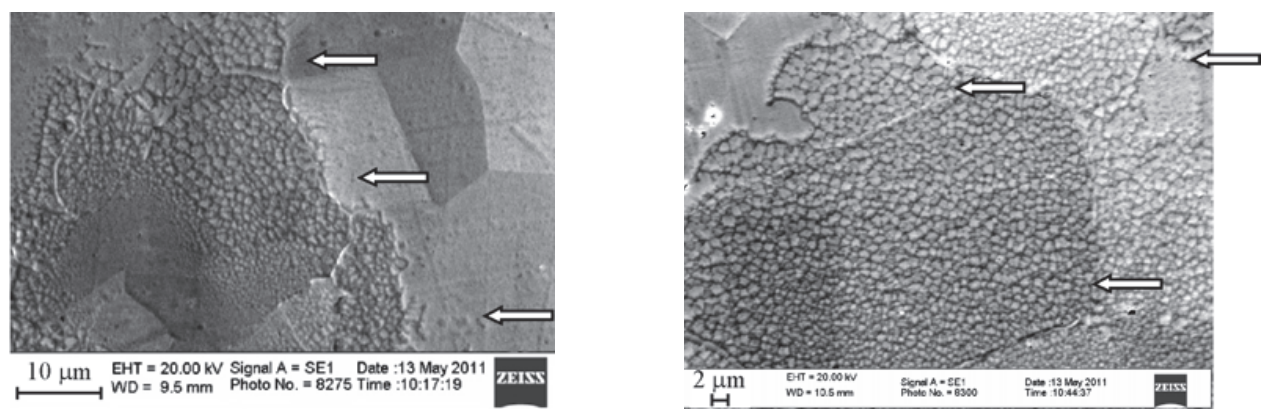

FIGURE 3. Bimodal polycrystalline structure of the $\mathrm{Ni}_{3} \mathrm{Al}$ intermetallic compound synthesized in a conical mold under plastic strain of the synthesis product (layer 3 of the conical intermetallic ingot). Arrows indicate submicron grains

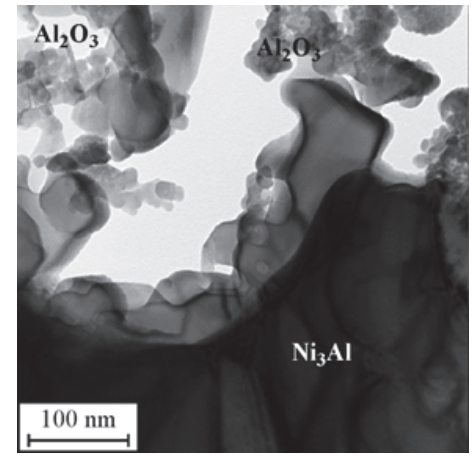

(a)

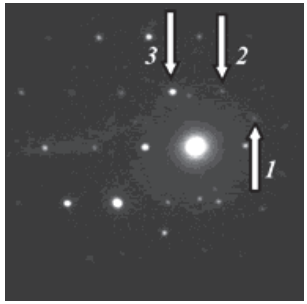

(b)

FIGURE 4. Electron microscopic image of the bimodal grain structure formed during the synthesis of the $\mathrm{Ni}_{3} \mathrm{Al}$ intermetallic compound (layer 5 of the conical intermetallic ingot) under pressure with plastic strain of the synthesis product; (a) is a bright-field image; (b) is micro electron diffraction pattern obtained from nanoscale grains; arrows on (b) show aluminum oxide reflections $\gamma-\mathrm{Al}_{2} \mathrm{O}_{3}$ (lattice parameters: $a=0.310 \mathrm{~nm}, c=0.499 \mathrm{~nm}$ ):

$$
1-[100], 2-[01 \overline{2}], 3-[\overline{1} 1 \overline{2}]
$$

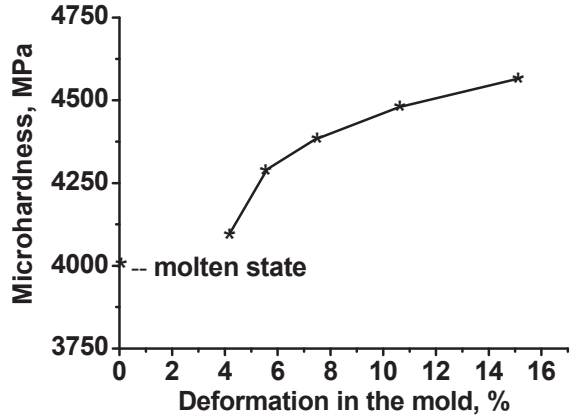

FIGURE 5. Influence of the high-temperature synthesis technology on the microhardness value of the $\mathrm{Ni}_{3} \mathrm{Al}$ intermetallic compoun 

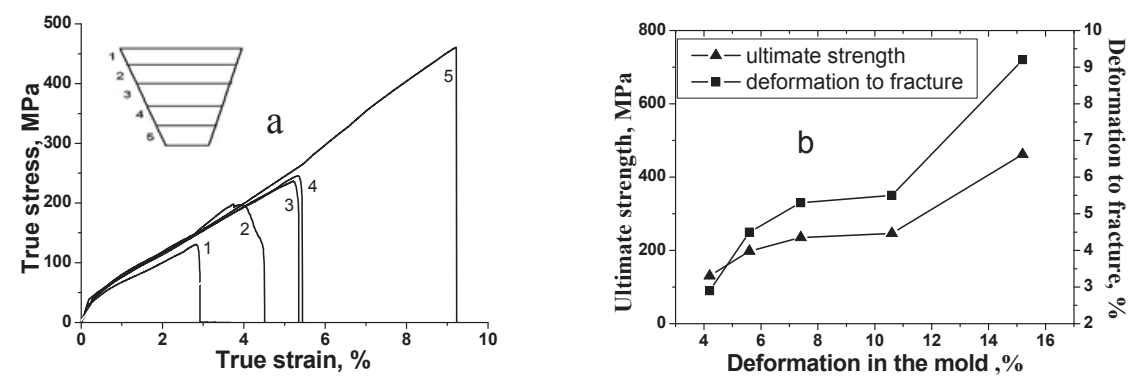

FIGURE 6. Stress-strain curves of the $\mathrm{Ni} 3 \mathrm{Al}$ intermetallic compound test pieces obtained from the transverse layers of the intermetallic compact synthesized under pressure via the plastic strain of the high-temperature synthesis product in a conical mold (a); the ultimate strength and deformation-to-fracture of the synthesized intermetallic compound as the functions of the degree of plastic deformation of the high-temperature synthesis product in a conical mold (b)

During the formation of a bimodal grain structure in the synthesized $\mathrm{Ni}_{3} \mathrm{Al}$ intermetallic compound, interlayers consisting of the nanoscale $\mathrm{Al}_{2} \mathrm{O}_{3}, \mathrm{Ni}_{2} \mathrm{Al}_{3}$ and $\mathrm{NiAl}$ crystallites are formed at the interfaces between individual micrograins of the $\mathrm{Ni}_{3} \mathrm{Al}$ intermetallic compound, as a result of the plastic deformation of the high-temperature synthesis product (Fig. 4).

\section{Mechanical Properties}

The investigation of the relationship between the microhardness of synthesized intermetallic compound and the degree of the high-temperature synthesis product's plastic strain showed that microhardness increases as the degree of plastic strain of the high-temperature synthesis product gets higher (Fig. 5).

$\mathrm{Ni}_{3} \mathrm{Al}$ intermetallic compound's yield strength, ultimate tensile strength and strain-to-fracture values get significantly higher as the degree of the plastic strain of the high-temperature synthesis product goes up. The tensile strength and strain-to-fracture of the synthesized $\mathrm{Ni}_{3} \mathrm{Al}$ intermetallic compound grow in multiples of their initial values as the degree of strain of the high-temperature synthesis product goes up (Fig. 6).

\section{CONCLUSIONS}

Plastic deformation of the $\mathrm{Ni}_{3} \mathrm{Al}$ intermetallic compound during its high-temperature synthesis in a nickelaluminum powder mixture of stoichiometric composition forms, a bimodal grain structure consisting of micron size grains, multigrains consisting of submicron size grains, and intergranular interlayers consisting of nanoscale $\mathrm{Al}_{2} \mathrm{O}_{3}$, $\mathrm{Ni}_{2} \mathrm{Al}_{3}$ and $\mathrm{NiAl}$ crystallites in the synthesized intermetallic compound.

Formation of a bimodal grain structure in the $\mathrm{Ni}_{3} \mathrm{Al}$ intermetallic compound has direct impact on the mechanical characteristics of the intermetallic compound, i.e. the intermetallic compound's microhardness significantly increases and its ultimate strength and deformation-to-fracture grow in multiples of their initial values.

\section{ACKNOWLEDGEMENT}

The research was done within the framework of fundamental research state academies of sciences for 2013-2020 and was supported by the Russian Foundation for Basic Research (Grant No. 13-08-98019).

\section{REFERENCES}

1. N. S. Stoloff, C. T. Liu, and S. C. Deevi, Intermetallics 8, 1313 (2000).

2. J. P. Lebrat and A. Varma, Combast. Sci. Technol. 88, 211 (1992).

3. A. G. Merzhanov, Ceram. Int. 21, 371 (1995).

4. J. J. Moore and H. J. Feng, Prog. Mater. Sci. 39, 243 (1995).

5. A. Hibino, S. Matsuoka, and M. Kiuchi, J. Mater. Process Technol. 112, 127 (2001).

6. L. Y. Sheng, W. Zhang, J. T. Guo, Z. S. Wang, V. E. Ovcharenko, L. Z. Zhou, and H. Q. Ye, Intermetallics 17, 572 (2009). 